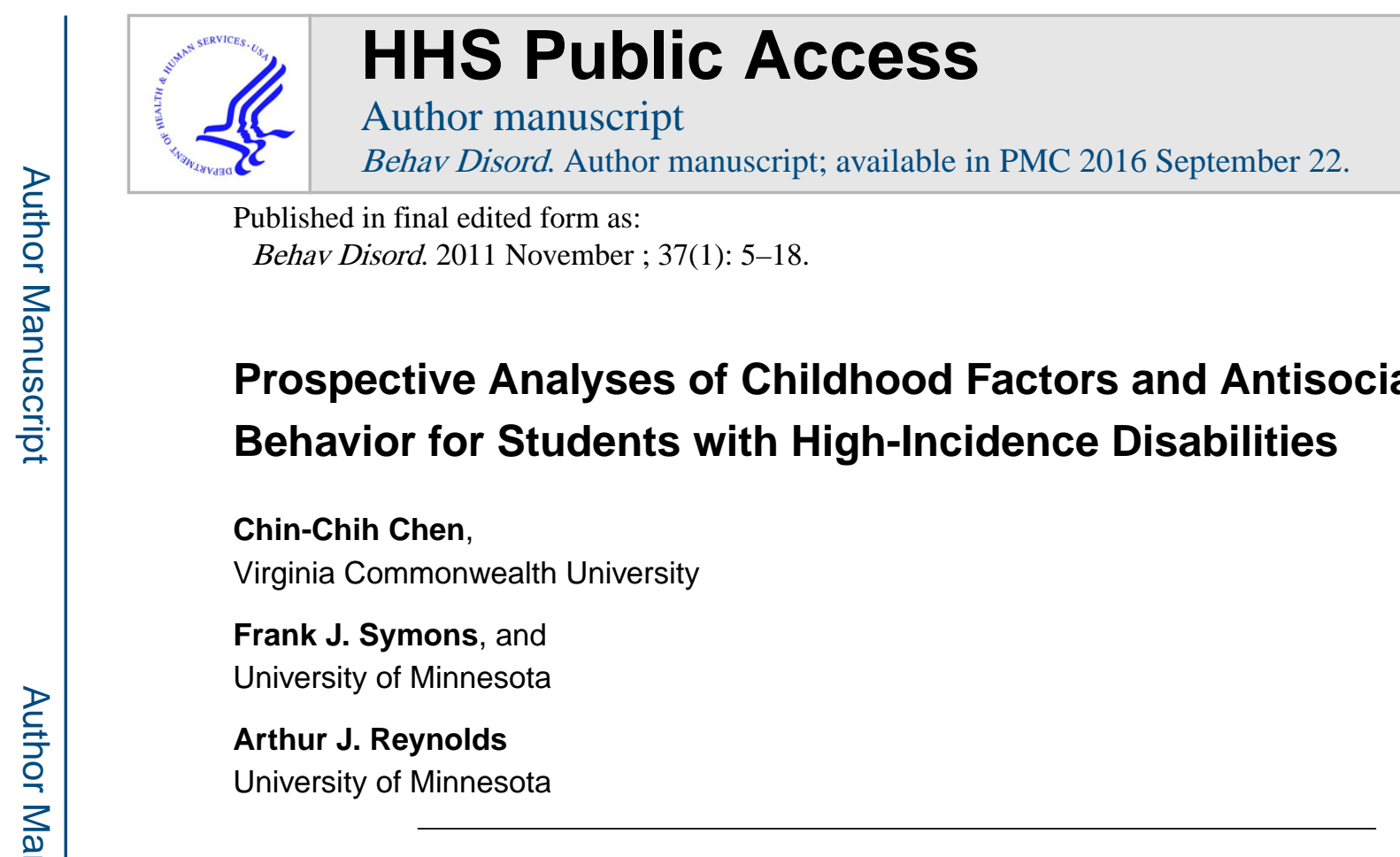

The disproportionate representation of students with learning disabilities (LD) and emotional disturbance (ED) in the correctional and criminal justice system has become a critical national concern (Quinn, Rutherford, Leone, Osher, \& Poirier, 2005). Over the last two decades, Casey and Keilitz (1990) indicated that the estimated prevalence of LD juvenile offenders was approximately $35.6 \%$ based on 21 studies. Murphy (1986) reported that the prevalence rates of ED in the correctional system ranged from $16 \%$ to $50 \%$.

Likewise, in the national reports (Newman, Wagner, Cameto, Knokey, \& Shaver, 2010), youth with ED and LD, identified as the most vulnerable students with disabilities in 1990 and 2005, respectively, had significantly higher arrest rates in the criminal justice system compared with other students with disabilities in early adulthood (the first 4 years out of high school; ED-36\% and 61\%, respectively; LD $16 \%$ and $24 \%$, respectively). The high prevalence rate of delinquent and criminal behavior for students with LD and ED has led to considerable social costs to meet their educational and mental health needs as well as the costs associated with correctional and criminal justice services. For the purpose of this paper, antisocial behavior refers to involvement with juvenile delinquency and adult crime.

Engaging in antisocial behavior such as juvenile delinquency and adult crime are associated with pervasive problems in community integration and involvement. Children and youth with LD or ED are more vulnerable and far less likely to make a successful transition to the community, as evidenced by their involvement in criminal justice system (Newman et al., 2010). Research examining the linkage between disabilities and antisocial behavior indicates that students with LD and ED have a higher risk of being arrested than students without LD and ED (Bryant et al., 1995; Doren, Bullis, \& Benz, 1996, Newman et al., 2010). The specific nature of the relation between high-incidence disability and later juvenile delinquency and criminal offences is not well understood, however, with some study results being less clear about their association (Jonson-Reid, Williams, \& Webster, 2001;

Malmgren, Abbott, \& Hawkins, 1999). Considering the breadth of the problem and the

Address correspondence to Chin-Chih Chen, Virginia Commonwealth University, 1015 W. Main St., Apt. No.501, Richmond, VA 23284; ccchen@vcu.edu. 
burden of support, one of the most pressing challenges in special education research and practice is to increase our understanding of salient factors that contribute to juvenile delinquency and adult crime for school-age children with LD and ED to inform effective interventions that enhance educational success and prevent adverse outcomes.

Research in this area has generated a number of hypothesized mechanisms between disabilities and delinquent and criminal behavior. School failure theory suggests that students with high-incidence disabilities tend to experience school failure (e.g., rejection experience, negative self-image, or frustration), which causes subsequent school dropout and delinquency (Osher, Woodruff, \& Sims, 2002). Susceptibility theory asserts that personality and cognitive deficits (e.g., impulsivity or inability to conceptualize causality) ultimately lead students with disabilities toward rule-breaking and eventual criminal and delinquent behavior (Waldie \& Spreen, 1993). Such hypothesized models, which do not address the complexity of the development of antisocial behavior, have been criticized for being too simplistic. The existence of disabilities might be a risk factor of subsequent antisocial behavior, but the scope and severity of problems vary considerably among students with disabilities throng the impact of the social contexts (Werner, 1999).

From an ecological perspective, variation in individual development is related to transactional influences within and between the individual and nested ecological systems (individual-dyads-classrooms-schools-neighborhoods, etc.; Bronfenbrenner, 1989). A variety of risk and protective factors from individual (e.g., temperament) to broader ecological contexts (e.g., family and school circumstances) are intertwined with individuals and their disabilities to exacerbate or reduce the likelihood of subsequent antisocial behavior (Keogh, 2000). Such individual and contextual factors, however, have not been thoroughly investigated among students with high-incidence disabilities across any appreciable timescales (Keogh, 2000). By far, the largest body of prior research work adopting an ecological perspective and addressing the effect of individual, family, peer, and school contexts on student development has focused on antisocial behavior. Among this body of work (reviewed briefly below), it is rare to find study samples and findings that are specific to school-age students with the special education service labels of LD and ED (most of the work is, in a sense, non-categorical and related to antisocial behavior). Through this work, however, important predictors relevant to outcomes for students with high-incidence disabilities have been identified.

\section{Individual factors}

Academic difficulties are considered one of the most important risk factors for the development of antisocial behavior. Evidence consistently shows that poor academic performance is related to subsequent delinquency and violent behavior (Loeber \& Farrington, 2000). Early literacy skills (e.g., word analysis) were associated with later juvenile delinquency (Reynolds, Ou, \& Topitzes, 2004). Among students with highincidence disabilities, evidence also shows the association between lower academic abilities and arrest status (Doren et al., 1996). However, some studies did not find relationships between reading and problem behavior for students with ED (Barton-Arwood, Wehby, \& Falk, 2005; Nelson, Stage, Epstein, \& Pierce, 2005; Wehby, Lane, \& Falk, 2003). 
Early problem behavior in childhood is also a critical individual determinant of later antisocial behavior. Early disruptive behavior and aggression consistently have been shown to be associated with later delinquent and criminal behavior in adolescence and adulthood (Loeber \& Farrington, 2000). For adolescents with ED, aggression in childhood was found to be associated with later antisocial behavior (Vance, Bowen, Fernandez, \& Thompson, 2002). Additionally, replicated findings show the relationship between social skill deficits and delinquency (Doren et al., 1996). Not surprisingly, classroom adaptive behavior (e.g., following directions and persistence in completing tasks) is associated with fewer disciplinary incidents at schools, but classroom maladaptive behavior is associated with more disciplinary incidents at schools for students with disabilities (Blackorby et al., 2007).

\section{Family factors}

Parent involvement and family support are considered necessary elements for promoting the educational success of students with disabilities and have been emphasized in special education policy since the mandate of P.L.94-142. Disrupted parenting practices, inconsistent and harsh discipline, and poor parent supervision are risk factors for delinquent and criminal behavior (Vance et al., 2002). Conversely, high family expectations and family involvement in schools or community are related to positive social adjustment and fewer disciplinary incidents (Blackorby et al., 2004; Newman \& Davis, 2004; Newman, Wagner, \& Guzman, 2002). Other family factors such as teenage mothering, family size (e.g., 4 or more children), family structure (e.g., single-parent), parent education, low family income, and parent unemployment predict later delinquent and criminal behavior (McHale, Obrzut, Sabers, 2003; Wagner et al., 2003). Similarly, child neglect/abuse (McCord, Widom, \& Crowell, 2001), low birth weight (Tibbetts \& Piquero, 1999) and prior child welfare services (Jonson-Reid \& Barth, 2000) are associated with a heightened risk of subsequent delinquent and criminal offenses.

\section{School factors}

School plays a critical, influential role in the development of children and youth. Providing opportunities for students to achieve mastery level accomplishments, facilitating academic performance, and ensuring support for academic and behavioral deficits reduces the likelihood of antisocial behavior (McEvoy \& Welker, 2000). Academic quality and school climate are negatively associated with school crime and violence levels (Verdugo \& Schneider, 1999). Blackorby et al. (2007) indicated that school factors (e.g., vocational courses, regular educational placement, support of social integration, and multidisciplinary collaboration) were positively associated with the social adjustment of children with disabilities.

School mobility places children and youth at risk for later antisocial behavior. It leads to unstable school environments and affects student academic difficulties and behavioral problems (Demie, 2002; Marder, Wagner, \& Sumi, 2003). Students with ED who experienced more school moves were vulnerable to subsequent adjustment difficulties, which often lead to school dropout and school incompletion (Tobin \& Sugai, 1999). On the other hand, early intervention for at-risk children and youth was associated with a decreased 
likelihood of being engaged in juvenile delinquency (Reynolds, Temple, Robertson, \& Mann, 2001).

As reviewed above, several contextual factors operating at the individual, family, and school level place children and youth at risk for later delinquent and criminal behavior. The majority of studies, however, considered the independent effects of single risk factors at single time points. It is likely that a complex interplay of multiple risk factors rather than single, isolated risk factors account for the emergence and progression of antisocial behavior (Wiener, 2003). One of our chief aims, therefore, was to disentangle the combined effect of contextual factors on antisocial behavior into adulthood for students with identified highincidence disabilities.

The majority of studies addressing antisocial behavior for students with disabilities, including those summarized above, are cross-sectional rather than longitudinal or experimental. It is difficult to identify possible directional influences between early determinants in the school years and later antisocial behavior. Among school-based populations, however, the precision of the work completed to date is limited by the fact that relatively few studies have examined the patterns of antisocial behavior specific to students with school-identified high-incidence disabilities (Blackorby et al., 2007). Additionally, clarifying whether students with LD and ED have differential patterns of determinants for developing antisocial behavior could, in turn, inform practitioners and policy-makers about the specific components of intervention services and resource allocation for students with high-incidence disabilities.

\section{The Current Study}

To address the limitations of the existing special education and related literature (crosssectional designs and isolated effects of single indicators), one of the novel aspect of this study is that we used a prospective, longitudinal approach informed by an ecological perspective designed to investigate the combined effects of childhood contextual factors on the behavioral development of students with high-incidence disabilities. There is a paucity of replicated research on adult crime for students with high-incident disabilities. Therefore, rather than examining single forms of antisocial behavior in isolation, we addressed agespecific manifestations of antisocial behavior including juvenile delinquency in late adolescence and adult crime into early adulthood.

The specific purpose of the study was to examine the effects of high-incidence disability status and combined effects of childhood contextual predictors on antisocial behavior. Accordingly, the following questions were addressed: a). Is student disability status (i.e., learning disabilities or emotional disturbance) associated with later antisocial behavior (juvenile delinquency and adult crime)?; $b$ ). Do individual, family, and school level characteristics predict later antisocial behavior?; and $c$ ). Does disability status moderate the relationships between individual, family, and school factors and later antisocial behavior? 


\section{METHOD}

\section{Sample}

The participants were drawn from the Chicago Longitudinal Study (CLS), an ongoing longitudinal study investigating the educational well-being and life course development of 1,539 ecologically disadvantaged, predominantly minority children (93\% African American). They were born in 1979 or 1980 and attended preschool or kindergarten programs in the Chicago Public Schools. The students in the Child-Parent Center (CPC) Program (989 children in 20 sites) received comprehensive education, family, and health services from age 3 . In the comparison group, it also included 550 children of the matched characteristics who enrolled in alternative programs in 5 Chicago public schools, which were randomly selected from 27 sites participating in the Chicago Effective School Project in similar, impoverished neighborhoods (see CLS, 1999).

The primary sample for this study consisted of 1,370 children in the CLS (89\% of the original sample). To include comprehensive information, participants were selected while they had active status information in the Chicago Public Schools and had at least one valid data point on the outcome measures to show whether students came into contact with juvenile justice or engaged in adult crime for the purpose of this study. The major demographic characteristics of the primary study sample are comparable to the original CLS sample (see Table 1). Approximately half (50.8\%) of the students were female. Students were predominately African-American (93.2\%). Students had approximately 5 early family risks indirectly indicating low child and family functioning and adjustment. Specifically, for early family risks at ages $0-3$, fewer than $55 \%$ of parents completed high school, $77.3 \%$ of family status was single-parent, $67 \%$ of mothers were unemployed, $84.8 \%$ of families were eligible for free school lunch, $16.7 \%$ of families had 4 or more children at home, $76.1 \%$ of children lived in school areas in which $60 \%$ or more children resided in low-income families, $16.4 \%$ of mothers were a teen parent at childbirth, and $63.7 \%$ of families received the Aid to Families with Dependent Children program (AFDC). Additionally, 11.8\% of children had low birthweight. Approximately four percent (3.9\%) of families had child welfare history at ages 0-3. In terms of early literacy skills, the mean standard score of student word analysis was 63.61 at age 5. The study sample in general represents vulnerable, economically disadvantaged children in an urban area. As for the status of general education and school remedial services among the 1,370 students, $8.8 \%$ of students were identified with $\mathrm{LD}(\mathrm{N}=121) ; 2.6 \%$ of students were identified with $\mathrm{ED}(\mathrm{N}=36) ; 5.8 \%$ of students were identified with other disabilities (e.g., hard of hearing, speech or language impairment, educable mentally handicapped, physically handicapped, other health impairment; $N=79$ ); $18.2 \%$ of students had grade retention histories but no special education placement $(\mathrm{N}=250)$; and $64.5 \%$ of students were general education students who did not receive any school remedial services $(\mathrm{N}=884)$.

Data regarding demographic attributes, individual, family and school experience, and behavioral outcomes were collected prospectively from birth to early adulthood. Covariate measures were conducted at ages 0-5. Predictor variables were primarily collected in elementary grades, at ages 7-12. Behavioral outcome variables were measured by age 18 
(juvenile delinquency) and by age 26 (adult arrest). Data were systematically collected from multiple sources including administrative data, standardized tests, student questionnaires, and teacher and parent surveys. Through on-going tracking, high rates of sample recovery for school records, behavioral outcomes, and explanatory variables were well maintained.

\section{Outcome Variables}

Juvenile delinquency-Juvenile delinquency was a dichotomous variable indicating poor social adjustment and conduct in adolescence. Juvenile delinquency was measured between 1990 and 1998 (ages 10-18) from administrative records including the Cook County juvenile court and two other mid-western locations. Juvenile arrest consisted of formal petitions of students who were arrested on criminal charges and went before a judge. Some petitions may have caused a warning or referral to social service agencies. Students with at least one juvenile arrest record by age 18 were coded 1 , and others were coded 0 .

Adult arrest-Adult arrest was a dichotomous variable that was measured by age 26 though official court reports of adult criminal records from the county, state, and federal level. County-level arrest data were gathered from court records in Cook County, Illinois. State-level arrest data were obtained primarily through the Illinois Department of Corrections, other mid-western states (Wisconsin, Iowa, and Minnesota), and the Department of Corrections system from nationwide states. Federal-level records were collected from the Federal Bureau of Prisons. Students with any adult arrest records by age 26 were coded 1 , and others were coded 0 .

\section{Predictor Measures: Disability Status, Individual, Family, and School}

Disability status-Disability status indicated students receiving general education or other school special or remedial services based on the school administrative records yearly in the Chicago Public Schools. The disability status and special education information included LD, ED, other disabilities, grade retention only, and general education without receiving any school remedial services (as reference group).

Academic achievement-Academic achievement was a continuous variable measured by the child's reading comprehension in grade 5 on the standardized group-administrated achievement test, the Iowa Test of Basic Skills (ITBS) (Hieronymus \& Hoover, 1990). ITBS raw scores were converted to developmental standard scores and used to determine cognitive growth over time and across grade levels. The reading scale consisted of 58 items that measured the understanding of text passages $(\alpha=.92)$.

Classroom adjustment-Classroom adjustment was a continuous variable indicating the social-emotional maturity in classrooms grades 4 through 6 . Classroom adjustment was measured by teacher ratings of socio-emotional maturity in schools based on six items, including "concentrates on work;" "follows directions;" "is self confident;" "gets along well with others;" "participants in group discussions;" and "takes responsibility for actions;" in which the child's performance was rated on a 5-point scale from poor to excellent ( $1=$ poor/not at all; $2=$ fair/some; $3=$ satisfactory/average; $4=$ above average; and 5= excellent/ much). The scale was administrated yearly. The internal reliability coefficient ranges from 
$a=.89$ to .91 . This variable has been used widely in prior studies related to educational wellbeing (Blackorby et al., 2007).

Parent participation in school-Parent participation in school was defined as the number of years of teacher ratings of parental participation in schools as average or better in grades 1 through 6 . Parent participation in the child elementary school experience was rated by teachers on a 5-point scale from yearly surveys (1=poor/not at all; $2=$ fair/some; $3=$ satisfactory/average; $4=$ above average; and 5=excellent/much). Prior studies have found that parent participation in school was associated with later educational-related outcomes (Blackorby et al., 2004; Newman et al., 2002).

Child abuse/neglect - Child abuse/neglect was a dichotomous variable indicating whether the child experienced a substantiated abuse/neglect based on the reports of the Child Protective System of the Illinois Department of Child and Family Services and/or court petitions to the Cook County juvenile system at ages 7 to12. Children with one or more substantiated reports of abuse and neglect petitions were coded 1 and children with no histories were coded 0 .

CPC program participation-Participation in the CPC preschool program was a dichotomous variable indicating whether the child attended a CPC preschool program using school administrative records from the Chicago Public Schools. The CPC preschool program includes language skills, the socialization of young children, parental involvement, comprehensive health and social services, and family support services (Reynolds et al., 2001). This program has been documented to benefit the achievement of economically disadvantaged children (Reynolds et al., 2001). Children participating in the CPC preschool program were coded 1 . Children in the comparison group with alternative programs were coded 0 .

School quality-School quality was measured by any magnet school attendance in grades 1 through 6. Data were obtained from school administrative records yearly in the Chicago Public Schools. Magnet schools are selective schools that provide specified curriculum and are presumably expected to have a positive school climate and a focus of academic success and pro-social behavior. Previous findings indicate that magnet school participation is associated with greater school achievement and social adjustment (Reynolds et al., 2004). Children who ever attended magnet schools were coded 1. Others were coded 0.

School mobility-School mobility was measured by the number of school moves that the child had in grades 1 through 6. Data were obtained from school administrative records yearly. School mobility reflects the instability of the learning environment. School mobility was found to be related to lower academic performance, higher dropout, and the occurrence of antisocial behavior (Doren et al, 1996; Temple \& Reynolds, 1999). 


\section{Covariates}

Several child and family background characteristics from ages 0 to 5 that may have potential influence on behavioral outcomes were statistically controlled for to clarify the relative contributions of the attributes to later antisocial behavior including the following.

Gender-Males were coded 0 and females were coded 1.

Race/ethnicity-Hispanics were coded 0 and Africa-Americans were coded 1.

Family risk index-Family risk index was a composite variable summing up eight dichotomous socioeconomic risk factors, which were associated with lower child and family related functioning and adjustment (Bendersky \& Lewis, 1994). The information of accumulative risks was collected from family surveys or school records. Family risk index included whether the mother completed high school, single-parent family status, maternal unemployment, eligibility for free lunch status, having 4 or more children in the household, residence in school attendance area in which $60 \%$ or more of children were from lowincome families, teenage mother at childbirth, and family attendance in the public assistance programs (i.e., AFDC) from birth to age 3 (range= $0-7$ ).

Low birthweight-Low birthweight was a dichotomous variable. A child was coded 1 if the birthweight was less than 2500 grams. The data were collected from birth records in 1979 and 1980 from the Illinois Department of Public Health.

Child welfare history-Child welfare history was a dichotomous variable that indicated whether the child or a family received child protective services or other child welfare services due to abuse or neglect reports at ages 0-3. The data included petitions to the juvenile court and referrals to the Child Protection Division of the Illinois Department of Children and Family Services.

Word analysis-Evidence has shown that early literacy skills were associated with later antisocial behavior (Reynolds et al., 2004). It was measured by the word analysis subscale scores from the ITBS at the end of kindergarten. There were 35 items that evaluated preliteracy skills. ITBS raw scores were converted to developmental standard scores, which in turn were used to report for student word analysis. The test manual indicated high internal consistency reliability .87 (Hieronymus, Lindquist, \& Hoover, 1980). Research also confirmed the predictive validity of this measure for later academic achievement of at-risk children (Reynolds et al., 2004).

\section{Data Analyses}

We used probit regression to estimate coefficients of dichotomous outcome variables (any official juvenile delinquency and adult crime). Logit and probit regression are used to estimate binary outcomes. Both models provide similar results for most of their applications. This study used probit regression to compute marginal effects, which denote the percentage change in the outcome variables corresponding to a one-unit change in the predictor, while holding constant other variables. To examine if the effects of the predictor variables on 
behavioral outcomes were attributed to child and family background characteristics, adjusted coefficients and mean differences were estimated with the statistical control of covariates including gender, race/ethnicity, family risk index, low birthweight, child welfare history, and word analysis. $P$ values of .05 and .01 were employed to identify whether the effects were significant statistically. $P$ value of .10 was used to denote marginally statistical effects.

For missing data, we based our analysis on the assumptions of missing at random (MAR). Missing data were imputed through multiple imputation procedures by STATA. The Imputation by Chained Equations (ICE) program in STATA was used to impute incomplete data 5 times. Results from the multiple-imputed dataset and non-imputed dataset were similar. Results are reported based on the multiple-imputed dataset.

\section{RESULTS}

The study examined the effects of high-incidence disability status and multifaceted predictors across ecological contexts on antisocial behavior. The findings reported corresponding to the research questions include (a) the adjusted main effect relationships between disability status, high-incidence disabilities in particular, and antisocial behavior; (b) the combined relationships between individual, family, and school factors and antisocial behavior; and (c) the moderating effects of high-incidence disabilities on the links between childhood factors and antisocial behavior.

\section{Association between Disability Status and Later Antisocial Behavior}

It was hypothesized that students with high-incidence disabilities would be more likely to be involved in juvenile delinquency and adult arrest compared to students with other disabilities or those without disabilities. To specify the impact of high-incidence disabilities on later antisocial behavior, this study further examined subgroup differences (See Table 2). The variations of antisocial behavioral outcomes were investigated for students with highincidence disabilities (LD and ED, respectively), other disabilities, and grade retention histories only, and compared with those of youth in general education. For the purpose of group comparisons, probit regression models with dummy variables representing subtypes of groups (with general education students as the reference group) were used to predict antisocial behavior.

When child and family background characteristics were controlled for, high-incidence disabilities were significantly associated with higher rates of juvenile delinquency and adult arrest. For juvenile delinquency, students with LD had a $7.1 \%$ higher rate in juvenile delinquency than general education students (.071, $p<.10)$. Students with ED had a $43.3 \%$ higher rate in juvenile delinquency compared to general education students $(.433, p<.001)$. For adult arrest, students with LD had a 9.3\% higher rate in adult arrest compared to general education students $(.093, p<.10)$. Students with ED had a $35.8 \%$ higher rate in adult arrest compared to general education students $(.358, p<.001)$. Overall, students with LD and ED tended to have higher rates of juvenile delinquency and adult arrest then general education students (with students receiving ED services being the most vulnerable). 


\section{Combined Effects of Individual, Family, and School Factors}

The extent to which individual, family, and school factors were associated with behavioral outcomes was further examined. This study investigated the combined effects of disability status as well as multiple contextual factors at the individual, family, and school levels on later antisocial behavior simultaneously while controlling for the covariates (see Table 3).

As shown in Table 3, when taking disability status and contextual factors across individual, family, and school together, only students with ED had higher rates of delinquent and criminal behavior than general education students (the reference group). This study found evidence for the influence of individual and contextual factors in childhood on juvenile delinquency in late adolescence and adult arrest in early adulthood. For individual factors, classroom adjustment was significantly associated with a decreased likelihood of being involved in juvenile delinquency $(-.008, p<.01)$ and adult arrest $(-.014, p<.001)$. For family factors, parent participation in school was only predictive of adult arrest $(-.020, p<$. 10). Child abuse/neglect was positively associated with an increased likelihood of juvenile delinquency (.093, $p<.05)$ and adult arrest $(.124, p<.05)$. For school factors, CPC program participation was only associated with a decreased likelihood of juvenile delinquency (-. $054, p<.05)$. School quality and school mobility, otherwise, were linked with adult arrest $(-.093$ and $.026, p<.10)$. Overall, besides the impact of disability status, individual (classroom adjustment), family (parent participation in school and child abuse/neglect), and school factors (CPC program participation, school quality, and school mobility) had differential effects on juvenile delinquency and adult arrest.

\section{Differential Patterns for Students with High-Incidence Disabilities?}

One of the study aims was to specify whether there were differential predictive patterns of the development of antisocial behavior for students with high-incidence disabilities. Separate subgroup analyses for high-incidence disabilities appeared less likely to show sufficient statistical significance due to the relatively small sample size and the corresponding reduction in statistical power (The results regarding specific subgroup analysis for LD and ED subgroups are available upon request). To avoid unreliable interpretations about the predictive effects and to increase the power to detect statistically significant differences, the interaction tests for the entire study sample were further applied as an alternative and a more appropriate approach to validate whether a differential effect existed for high-incidence disabilities (Pocock, Assmann, Enos, \& Kasten, 2002). The model included dummy variables for disability status and interaction terms of individual, family, and school level factors multiplied by LD and ED (see Table 4).

As shown in Table 4, there were no moderating effects of high-incidence disability status. The relationship between contextual factors and antisocial behavior did not vary as a function of high-incidence disability status. Findings showed differential predictive patterns for each antisocial outcome (juvenile delinquency and adult arrest). For individual factors, classroom adjustment was significantly associated with a decreased likelihood of being involved in juvenile delinquency $(-.008, p<.01)$ and adult arrest $(-.014, p<.001)$. For family factors, parent participation in school and child abuse/neglect were not predictive of later juvenile delinquency and adult arrest while further controlling for the moderating 
effects of high-incidence disabilities status. For school factors, CPC program participation was only significantly associated with a decreased likelihood of juvenile delinquency (-.050, $p<.05)$. School quality was associated with a decreased likelihood of juvenile delinquency $(-.062, p<.10)$ and adult arrest $(-.112, p<.05)$. Additionally, school mobility were only linked with adult arrest $(.044, p<.01)$. Overall, based on the interaction tests, there was no evidence of moderating effects for high-incidence disabilities on the relationships between individual, family, and school level factors on later antisocial behavior. Students with highincidence disabilities did not have differential patterns of individual, family, and school level factors on antisocial behavior compared with all of the other students in the entire sample.

\section{DISCUSSION}

The primary purpose of this longitudinal study was to examine prospectively whether students identified with high-incidence disabilities were more likely to go on to have antisocial behavior than students without disabilities. This study is one of the first to investigate prospectively distinct manifestations of antisocial behavior from late adolescence into young adulthood. Consistent with prior studies (Bryant et al., 1995; Doren et al., 1996, Newman et al., 2010), we found that children identified with and receiving services for LD and ED tended to exhibit significant behavioral deficits or later antisocial behavior compared to students without disabilities, regardless of child and family background factors.

Additionally, this study provided an opportunity to explore differences between students with LD and ED. Students with LD only experienced slightly higher rates of antisocial behavior compared to general education students. Students identified with ED, however, consistently had higher rates of juvenile delinquency and adult arrest. Overall, the current results imply that the presence of disabilities, in and of itself, is a risk factor predicting juvenile delinquency and adult arrest. The adult arrest data is novel, troubling, and especially significant for contemporary policy planners considering resource allocation, accountability, and student outcomes.

Long standing antisocial behavior is complexly determined by multifaceted factors in various domains such as individual, family, and school ecologies (Loeber \& Farrington, 2000). Heterogeneous childhood predictors related to antisocial behavior were further identified in this longitudinal study while controlling for early child and family risks. Several childhood factors had an impact on antisocial behavior. At the individual level, classroom adjustment was a strong and consistent predictor for different manifestations of antisocial behavior. At the family level, parent participation in school had effects on adult arrest. The effect of child abuse/neglect was discernable for juvenile delinquency and adult arrest. School factors (i.e., CPC program participation, school quality, school mobility) were associated with delinquent and criminal behavior in adolescence and adulthood. Importantly, for both policy and practice, all of the above variables are, in principle, amenable to alteration or accommodation.

Individual level-Consistent findings have shown that academic difficulties are one of the most important risk factors for the development of antisocial behavior (Doren et al., 1996; Loeber \& Farrington, 2000). In this study, however, we did not find any significant 
associations between reading comprehension and antisocial behavior above and beyond the contributions of other predictors and covariates. The non-significant association between reading comprehension and juvenile delinquency and adult arrest might be due to the complicated relationships with classroom adjustment and other family and school level factors, which likely overpowered the effects of reading comprehension.

The current study found a robust association between classroom adjustment and antisocial behavior. Positive classroom adjustment was consistently associated with lower rates of juvenile delinquency and adult arrest above and beyond other predictors. Consistent with previous findings, classroom adaptive behavior was associated with fewer disciplinary incidents and less delinquent behavior at school for students with disabilities (Blackorby et al., 2007; Doren et al., 1996). This consistent and robust finding of the classroom adjustment-antisocial behavior association implies a component of preventive intervention practices. Classroom adjustment is a malleable protective factor in school settings. For educational practitioners, enhancing children's classroom adjustment could help to minimize the risk of developing antisocial behavior later in adolescence and adulthood.

Family level—Family involvement and support are also associated with social adjustment and fewer disciplinary incidents for students with disabilities (Blackorby et al., 2004; Newman \& Davis, 2004; Newman, et al., 2002). In the current study, parent participation in school activities appeared to be linked with adult arrest. The impact of parent participation in school did not, however, predict juvenile delinquency above and beyond other predictors. The inconsistent results might be due to the specific measure used, which relied on teacher ratings instead of parent reports. In addition, the relation between family factors and antisocial behavior included only parent participation in school activities, not in home settings. Therefore, the relationship between parent participation in school and later antisocial behavior might not be clearly discernable due to the lack of complementary measures of parent involvement. On the other hand, child abuse/neglect was associated with juvenile delinquency and adult arrest. The current results are similar to previous findings that child neglect/abuse was associated with a highlighted risk of subsequent delinquent and criminal offenses (McCord et al., 2001).

School level-Prior studies indicated that early intervention for at-risk children and youth were associated with a decreased likelihood of being engaged in juvenile delinquency (Reynolds et al., 2001). Similar to previous findings, the current study found that CPC program participation was associated with a decreased likelihood of juvenile delinquency. The impact of CPC program participation did not persist for adult arrest. Further research will be necessary to examine whether CPC program participation is differentially associated with any dimension of later adult crime (frequency, severity, or variety).

School quality was associated with a decreased likelihood of juvenile delinquency and adult arrest in this study. Evidence has shown that the academic quality and school climate is associated with the level of school crime and violence (Verdugo \& Schneider, 1999). Unstable learning settings lead to student academic difficulties and behavioral problems (Demie, 2002; Marder et al., 2003). Schools could possibly play a more active role to reduce the risk and prevent students getting onto the path of juvenile delinquency and adult crime. 
On the other hand, this study indicated that school mobility had significant predictive effects on adult arrest, suggesting that academic and social instability in school contexts may be associated with increased rates of adult arrest. Nevertheless, school mobility was not associated with juvenile delinquency. School mobility may be related to other variables such as poor student-teacher relationships, peer relationships, low academic performance, or school dropout, which impact juvenile delinquency. The indirect effects need to be investigated to understand the pathways between school mobility and antisocial behavior.

Importantly, the interaction tests indicated that the predictive effects of individual, family, and school factors on juvenile delinquency and adult crime did not vary by high-incidence disability status. The findings helped to validate the patterns of behavioral outcomes for high-incidence disabilities and increased the power to detect predictive effects. This is a novel finding suggesting that students with ED and LD did not have differential predictive patterns of antisocial behavior in relation to different ecological factors. If that is true (it needs to be replicated), it may mean that while high quality evidence-based prevention and intervention services are needed they may not need to be broken into specialized components that are necessarily LD or ED specific.

\section{Limitations and Implications for Future Research}

Individual characteristics and experience within family and school contexts are interrelated and influence antisocial behavior. As with any single study we did not fully disentangle the complexity of the mechanisms underlying antisocial behavior. It is unlikely that any single study can. Given the transactions among individual, social, familial, and behavioral variables, further research needs to examine mediating effects to understand the relevant developmental mechanisms leading to juvenile delinquency and adult crime. Transactional models involving interactive linkages among multiple levels of variables over time (e.g., psychobiological, familial, peer-related, and wider social contexts) should be examined. Evidence of causality can be obtained by more sophisticated analyses such as structural equation models controlling for a greater array of confounding variables. The goal of identifying the most relevant mechanisms is to tailor that knowledge to developing or planning treatments that target developmental mechanisms with more precision and at the right time.

The influence of individual and contextual factors on the development of antisocial behavior may vary across the life course (Tremblay \& LeMarquand, 2001). However, the findings in this study are limited because most individual, family, and school factors used in this study were collected in elementary grades. Factors proximal to juvenile delinquency and adult arrest such as deviant peer affiliations or neighborhood characteristics appear to exert more influence on antisocial behavior. Otherwise, family influence had less influence on juvenile delinquency than deviant peer affiliations, which indicates a shift from family to peer influence (Dishion, Patterson, Stoolmiller, \& Skinner, 1991). Future research needs to testify whether specific effects affect the emergence and progression of antisocial behavior during specific developmental period or across the life span.

The subjectivity of the school-identified LD and ED codes has been an issue for decades, and theoretically plays a role in how students are treated academically and behaviorally 
throughout their school careers. Some rare exchanges of LD and ED codes were found throughout student school careers when student disability status was identified based on their primary disability categories. Future research might shed light on the variation of disability codes within LD and ED population and investigate the changes in disability status and services on later academic and behavior outcomes.

The generalizability of the current results to other areas or populations was limited because the study sample was specifically drawn from one school district and the same cohort of low-income children. Using the existing dataset from the CLS, the sample was representative of at-risk children in a low-income area in Chicago, who attended early childhood intervention programs. The current results may not be generalized to students living in rural areas because the participants lived in impoverished urban areas. Furthermore, most of the sample was predominantly African-American. Therefore, generalizability of the research results to other race/ethnicity groups is limited.

\section{Implications for Policy and Practice}

This study addressed behavioral outcomes of social importance and great concern to policy makers and practitioners. The adult arrest outcome data are especially troublesome. On the positive side, findings indicated potentially malleable risk factors (child abuse/neglect and school mobility) and protective factors (classroom adjustment, parent participation in school, preschool program participation, and school quality) in childhood. The results further support steps taken by applied investigations and practitioners to design interventions based on relevant ecologies. The current results suggest the continued need for educational or social services to develop strategies to reduce antisocial behavior by attenuating risk factors and strengthening children's individual, family and school resources. Professionals working with children and youth in the educational and child welfare systems are required to help the target group who are in need of or at risk for later antisocial behavior through cross-agency collaboration.

The study outcomes are also relevant for policy questions regarding the overrepresentation of students with disabilities, in particular LD and ED, in juvenile and criminal justice system. Increased awareness of the likely antisocial behavior of students with high-incidence disabilities should inform criminal justice policy providing an opportunity to build a supportive and preventive service system. A disproportionate number of youth in the correctional system have disabilities and mental health issues. To help vulnerable youth with disabilities in the justice system, integrated programs should be developed between school and the juvenile justice system to help students rehabilitate and make the transition into the mainstream of school contexts (McHale et al., 2003). Furthermore, funding and building a inter-agency coordination among educational systems, justice systems, and communities system to support for high school completion, transition planning, and career preparation are necessary for helping students make the transition to employment and enhance social interaction in community life. 


\section{Conclusion}

The purpose of this study was to examine prospectively the influence of high-incidence disability status and multifaceted ecological factors on juvenile delinquency and adult arrest. From a methodological perspective, most comparable studies in special education have a myriad of methodological problems, most notably are cross-sectional, and almost always lack a comparison group. Findings in this study may warrant higher levels of confidence than previous studies because of the prospective longitudinal data and an extensive set of control variables. The interaction tests used in this study further increase the power to detect statistically significant differences and make reliable interpretations about predictive effects. The predictive value for adult crime is deeply disturbing. These new findings reflect the specialized and difficult challenges for schools and families in meeting educational and social needs for children with high-incidence disabilities. Understanding the influence of malleable risk and protective factors in childhood on antisocial behavior should help researchers and practitioners further develop and test effective practices to alter the developmental liabilities of students with high-incidence disabilities and reduce the later cost for schools and society.

\section{Acknowledgments}

This research is supported by grants from the National Institute of Child Health and Human Development (R01HD034294).

\section{References}

Barton-Arwood SM, Wehby JH, Falk KB. Reading instruction for elementary-age students with emotional and behavioral disorders: Academic and behavioral outcomes. Exceptional Children. $2005 ; 72: 7-27$.

Blackorby, J.; Knokey, A.; Wagner, M.; Levine, P.; Schiller, E.; Sumi, C. SEELS: What makes a difference? Influences on outcomes for students with disabilities. 2007. Retrieved March 31, 2007, from http://www.seels.net/infoproduct.htm

Blackorby, J.; Wagner, M.; Cameto, R.; Davies, E.; Levine, P.; Newman, L., et al. SEELS: Engagement, academics, social adjustment, and independence: The achievements of elementary and middle school students with disabilities. 2004. Retrieved March 31, 2007, from http:// www.seels.net/infoproduct.htm

Bronfenbrenner U. Ecological systems theory. Annals of Child Development. 1989; 6:187-249.

Bryant ES, Rivard JC, Addy CL, Hinkle KT, Cowan TM, Wright G. Correlates of major and minor offending among youth with severe emotional disturbance. Journal of Emotional and Behavioral Disorders. 1995; 3:76-84.

Casey, P.; Keilitz, I. Estimating the prevalence of learning disabled and mentally retarded juvenile offenders: A meta-analysis. In: Leone, PE., editor. Understanding troubled and troubling youth. Sage; Newbury Park, CA: 1990. p. 80-101.

CLS, Chicago Longitudinal Study. A study of children in the Chicago public schools: User's guide. University of Wisconsin; Madison, WI: 1999. Version 6

Demie F. Pupil mobility and educational achievement in schools: An empirical analysis. Educational Research. 2002; 44:197-216.

Dishion TJ, Patterson GR, Stoolmiller M, Skinner ML. Family, school, and behavioral antecedents to early adolescent involvement with antisocial peers. Developmental Psychology. 1991; 27:172-180.

Doren B, Bullis M, Benz MR. Predicting the arrest status of adolescents with disabilities in transition. The Journal of Special Education. 1996; 29:363-380. 
Hieronymus, AN.; Hoover, HD. Iowa Tests of Basic Skills: A Manual for School Administrators. Riverside Publishing Company; Chicago: 1990. University of Iowa

Hieronymus, AN.; Lindquist, EF.; Hoover, HD. Iowa Tests of Basic Skills: Primary battery. Riverside Publishing; Chicago: 1980.

Jonson-Reid M, Barth RP. From maltreatment report to juvenile incarceration: The role of child welfare services. Child Abuse and Neglect. 2000; 24:505-520. [PubMed: 10798840]

Jonson-Reid M, Williams JH, Webster D. Severe emotional disturbance and violent offending among incarcerated adolescents. Social Work Research. 2001; 25:213-222.

Keogh BK. Risk, families, and schools. Focus on Exceptional Children. 2000; 33:1-10.

Loeber R, Farrington DP. Young children who commit crime: epidemiology, developmental origins, risk factors, early interventions, and policy implications. Development and Psychopathology. 2000; 12:737-762. [PubMed: 11202042]

Malmgren K, Abbott RD, Hawkins JD. LD and delinquency: Rethinking the "link". Journal of Learning Disabilities. 1999; 32:194-200. [PubMed: 15508239]

Marder, C.; Wagner, M.; Sumi, C. The social adjustment of youth with disabilities. 2003. Retrieved March 31, 2007, from http://www.seels.net/infoproduct.htm

McCord, J.; Widom, CS.; Crowell, NA., editors. Juvenile crime, juvenile justice. National Academy Press; Washington, DC: Report from the National Research Council and the Institute of Medicine

McEvoy A, Welker R. Antisocial behavior, academic failure, and school climate: A critical review. Journal of Emotional and Behavioral Disorders. 2000; 8:130-140.

McHale BG, Obrzut JE, Sabers DL. Relationship of cognitive functioning and aggressive behavior with emotionally disabled and specific learning disabled students. Journal of Developmental and Physical Disabilities. 2003; 15:123-140.

Murphy DM. The prevalence of handicapping conditions among juvenile delinquents. Remedial and Special Education. 1986; 7:7-17.

Newman, L.; Davis, E. The school engagement of elementary and middle school students with disabilities. 2004. Retrieved March 31, 2007, from http://www.seels.net/infoproduct.htm

Newman, L.; Wagner, M.; Guzman, AM. Family supports for education at home. 2002. Retrieved March 31, 2007, from http://www.seels.net/infoproduct.htm

Newman, L.; Wagner, M.; Cameto, R.; Knokey, AM.; Shaver, D. Comparisons across time of the outcomes of youth with disabilities up to 4 years after high school. A report of findings from the National Longitudinal Transition Study-2 (NLTS2). SRI International; Menlo Park, CA: 2010. Available at www.nlts2.org/reports/2010_09/nlts2_report_2010_09_complete.pdf

Osher, D.; Woodruff, D.; Sims, A. Schools make a difference: The relationship between education services for African American children and youth and their overrepresentation in the juvenile justice system. In: Losen, D., editor. Minority issues in special sducation. Harvard University and the Harvard Education Publishing Group; Cambridge, MA: 2002. p. 93-116.

Pocock SJ, Assmann SE, Enos LE, Kasten LE. Subgroup analysis, covariate adjustment and baseline comparisons in clinical trial reporting: current practice and problems. Statistics in Medicine. 2002; 21:2917-2930. [PubMed: 12325108]

Quinn MM, Rutherford RB, Leone PE, Osher DM, Poirier JM. Students with disabilities in detention and correctional settings. Exceptional Children. 2005; 71:339-345.

Reynolds AJ, Ou S, Topitzes JW. Paths of effects of early childhood intervention on educational attainment and delinquency: A confirmatory analysis of the Chicago Child-Parent Centers. Child Development. 2004; 75:1299-1338. [PubMed: 15369516]

Reynolds AJ, Temple JA, Robertson DL, Mann EA. Long-term effects of an early childhood intervention on educational achievement and juvenile arrest: A 15-year follow-up of low income children in public schools. JAMA. 2001; 285:2339-2346. [PubMed: 11343481]

Temple JA, Reynolds AJ. School mobility and achievement: Longitudinal results from an urban cohort. Journal of School Psychology. 1999; 37:355-377.

Tibbetts SG, Piquero AR. The influence of gender, low birth weight, and disadvantaged environment in predicting early onset of offending: A test of Moffitt's interactional hypothesis. Criminology. 1999; 37:834-877. 
Tobin T, Sugai G. Discipline problems, placements, and outcomes for students with serious emotional disturbance. Behavioral Disorders. 1999; 24:109-121.

Tremblay, RE.; LeMarquand, D. Individual and protective risk factors. In: Loeber, R.; Farrington, DP., editors. Child Delinquents: Development, interventions and service needs. Sage; Thousand Oaks, CA: 2001. p. 137-164.

Vance JE, Bowen NK, Fernandez G, Thompson S. Risk and protective factors as predictors of outcome in adolescents with psychiatric disorders and aggression. Journal of the American Academy of Child and Adolescent Psychiatry. 2002; 41:36-43. [PubMed: 11800203]

Verdugo R, Schneider J. Quality schools, safe schools: a theoretical and empirical discussion. Education and Urban Society. 1999; 31:286-308.

Wagner, M.; Marder, C.; Blackorby, J.; Cameto, R.; Newman, L.; Levine, P., et al. The achievements of youth with disabilities during secondary school. 2003. Retrieved March 31, 2007, from http:// www.nlts2.org/pdfs/achievements_ywd_sec_school.pdf

Waldie K, Spreen O. The relationship between learning disabilities and persisting delinquency. Journal of Learning Disabilities. 1993; 26:417-423. [PubMed: 8354946]

Wehby JH, Lane KL, Falk KB. Academic instruction for students with emotional and behavioral disorders. Journal of Emotional and Behavioral Disorders. 2003; 11:194-197.

Werner, EE. Risk and protective factors in the lives of children with high-incidence disabilities. In: Gallimore, R.; Bernheimer, LP.; Macmillan, DL.; Speece, DL.; Vaughn, S., editors. Developmental perspectives on children with high-incidence disabilities. Lawrence Erlbaum; Mahwah, NJ: 1999. p. $15-32$.

Wiener J. Resilience and multiple risks: A response to Wong. Learning Disabilities study \& Practice. 2003; 18:77-81. 
Table 1

Demographic Characteristics for the Original Sample and Primary Study Sample

\begin{tabular}{|c|c|c|}
\hline \multirow[b]{2}{*}{ Variables } & Original Sample & Primary Study Sample \\
\hline & $N=1539$ & $N=1370$ \\
\hline Gender (female, \%) & 50.3 & 50.8 \\
\hline Race/ethnicity (African-American, \%) & 92.9 & 93.2 \\
\hline Family risk index (ages 0-3) & 4.5 & 4.6 \\
\hline $\begin{array}{l}\text {-Maternal education-mother did not } \\
\text { complete high school (ages } 0-3, \% \text { ) }\end{array}$ & 54.3 & 54.3 \\
\hline $\begin{array}{l}\text {-Single-parent family status (ages 0-3, } \\
\% \text { ) }\end{array}$ & 76.5 & 77.3 \\
\hline -Mother unemployment (ages 0-3, \%) & 66.3 & 67.0 \\
\hline -Eligibility for free lunch (ages 0-3, \%) & 83.8 & 84.8 \\
\hline $\begin{array}{l}\text {-Family structure-having } 4 \text { or more } \\
\text { children at home (ages } 0-3, \% \text { ) }\end{array}$ & 16.6 & 16.7 \\
\hline $\begin{array}{l}\text {-Neighborhood indicator- } 60 \% \text { or more } \\
\text { children reside in low-income } \\
\text { families (ages } 0-3, \% \text { ) }\end{array}$ & 76.0 & 76.1 \\
\hline $\begin{array}{l}\text {-Teenage mother at childbirth (<age } \\
\quad 18, \%)\end{array}$ & 16.2 & 16.4 \\
\hline -AFDC (ages 0-3, \%) & 62.8 & 63.7 \\
\hline Low birthweight $(<2,500 \mathrm{gms}, \%)$ & 11.8 & 11.8 \\
\hline Child welfare history (ages 0-3, \%) & 3.8 & 3.9 \\
\hline $\begin{array}{l}\text { Word analysis (age } 5 \text {, mean standard } \\
\text { score) }\end{array}$ & 63.8 & 63.6 \\
\hline
\end{tabular}


Table 2

High Incidence Disabilities and Juvenile Delinquency and Adult Arrest

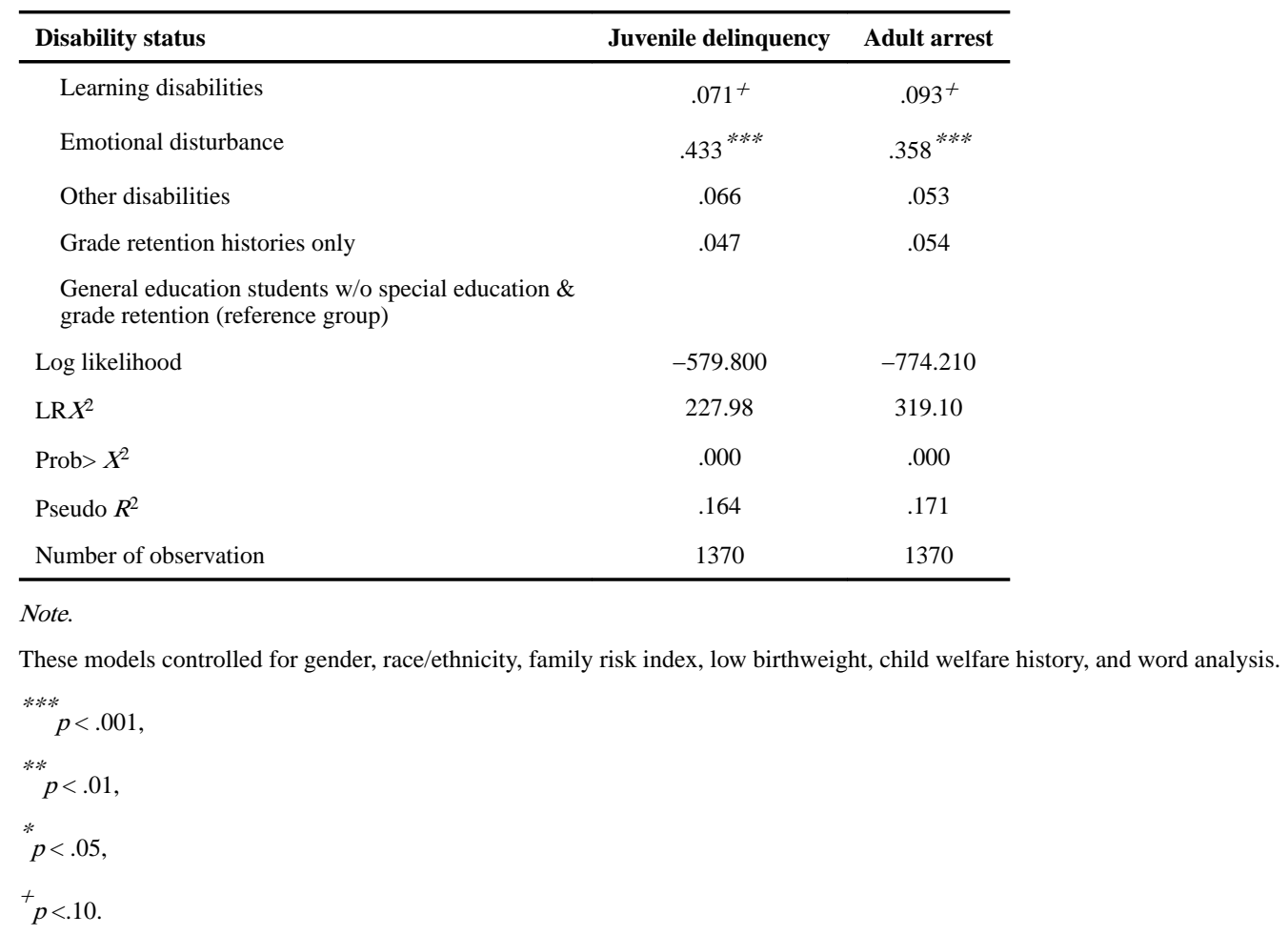


Table 3

Individual, Family, and School Factors Predicting Juvenile Delinquency and Adult Arrest

\begin{tabular}{lcc}
\hline Predictors & Juvenile delinquency & Adult arrest \\
\hline Disability status & & \\
$\quad$ Learning disabilities & .018 & .008 \\
Emotional disturbance & $.371^{* * *}$ & $.278^{*}$ \\
Other disabilities & .038 & .026 \\
Grade retention histories only & .009 & -.011 \\
General education students w/o special education \& & & \\
grade retention (reference group) & & \\
Individual, family, \& school level & & -.001 \\
Reading comprehension & -.001 & $-.014^{* * *}$ \\
Classroom adjustment & $-.008^{* *}$ & $-.020^{+}$ \\
Parent participation in school & -.012 & $.124^{*}$ \\
Child abuse/neglect & $.093^{*}$ & .004 \\
CPC program participation & $-.054^{*}$ & $-.093^{+}$ \\
School quality & -.049 & $.026^{+}$ \\
School mobility & -.004 & -752.275 \\
Log likelihood & -563.998 & 362.97 \\
LR $X^{2}$ & 259.58 & .000 \\
Prob> $X^{2}$ & .000 & .194 \\
Pseudo $R^{2}$ & .187 & 1370 \\
Number of observation & 1370 & \\
\hline
\end{tabular}

Note.

These models controlled for gender, race/ethnicity, family risk index, low birthweight, child welfare history, and word analysis.

****

$p<.001$,

**

$p<.01$,

* $p<.05$,

${ }^{+} p<.10$. 
Table 4

Moderating Effects of High-Incidence Disabilities on Individual, Family, and School Factors Predicting Juvenile Delinquency and Adult Arrest

\begin{tabular}{|c|c|c|}
\hline Predictors & Juvenile delinquency & Adult arrest \\
\hline \multicolumn{3}{|l|}{ Disability status } \\
\hline Learning disabilities & -.131 & -.312 \\
\hline Emotional disturbance & .510 & -.417 \\
\hline Other disabilities & .034 & .022 \\
\hline Grade retention histories only & .004 & -.024 \\
\hline \multicolumn{3}{|c|}{$\begin{array}{l}\text { General education students w/o special education \& } \\
\text { grade retention (reference group) }\end{array}$} \\
\hline \multicolumn{3}{|l|}{ Individual, family, \& school level } \\
\hline Reading comprehension & -.001 & -.002 \\
\hline Classroom adjustment & $-.008^{* *}$ & $-.014^{* * *}$ \\
\hline Parent participation in school & -.013 & -.016 \\
\hline Child abuse/neglect & .077 & .099 \\
\hline $\mathrm{CPC}$ program participation & $-.050^{*}$ & .017 \\
\hline School quality & $-.062^{+}$ & $-.112^{*}$ \\
\hline School mobility & -.001 & $.044^{* * *}$ \\
\hline \multicolumn{3}{|l|}{ Interaction terms } \\
\hline LD $\times$ Reading comprehension & .002 & .008 \\
\hline $\mathrm{LD} \times$ Classroom adjustment & .002 & -.016 \\
\hline LD $\times$ Parent participation in school & -.006 & -.031 \\
\hline LD $\times$ Child abuse $/$ neglect & .055 & .071 \\
\hline $\mathrm{LD} \times \mathrm{CPC}$ program participation & -.063 & -.042 \\
\hline LD $\times$ School quality & .282 & .360 \\
\hline LD $\times$ School mobility & -.017 & -.082 \\
\hline $\mathrm{ED} \times$ Reading comprehension & -.002 & .019 \\
\hline $\mathrm{ED} \times$ Classroom adjustment & -.001 & .189 \\
\hline $\mathrm{ED} \times$ Parent participation in school & .034 & -.161 \\
\hline $\mathrm{ED} \times$ Child abuse/neglect & .137 & --- \\
\hline $\mathrm{ED} \times \mathrm{CPC}$ program participation & .200 & -.481 \\
\hline ED $\times$ School quality & --- & --- \\
\hline ED $\times$ School mobility & -.003 & -.144 \\
\hline Log likelihood & -559.904 & -737.963 \\
\hline $\mathrm{LR} X^{2}$ & 267.77 & 381.27 \\
\hline Prob $>X^{2}$ & .000 & .000 \\
\hline Pseudo $R^{2}$ & .193 & .205 \\
\hline Number of observation & 1370 & 1370 \\
\hline
\end{tabular}

Note.

These models controlled for gender, race/ethnicity, family risk index, low birthweight, child welfare history, and word analysis. "---" variable is dropped because of collinearity or predicting failure perfectly. 
**** $p<.001$,

** $p<.01$,

$\geq \quad p<.05$

음 $\quad{ }^{+} p<10$. 